\title{
Knowledge, attitudes and practices in the control and prevention of malaria in four endemic provinces of Zambia
}

\author{
Nzooma M. Shimaponda-Mataa ${ }^{a b *}$, Enala Tembo-Mwase ${ }^{c}$, Michael Gebreslasie $^{d}$ and Samson Mukaratirwa $^{b}$ \\ ${ }^{a}$ Department of Biomedical Sciences, University of Zambia School of Medicine, Lusaka, Zambia \\ ${ }^{b}$ School of Life Sciences, University of KwaZulu-Natal, Durban, South Africa \\ 'School of Veterinary Medicine, University of Zambia, Lusaka, Zambia \\ 'School of Agriculture, Earth and Environmental Science, University of KwaZulu-Natal, Durban, South Africa \\ *Corresponding author, email:nzomataa@gmail.com
}

This study sought to determine malaria knowledge levels, attitudes and practices of the communities in four malaria endemic provinces of Zambia. A cross-sectional survey on knowledge, attitude and practices (KAP) on malaria transmission, prevention and control was conducted among 584 household heads of randomly selected communities in Luapula, Lusaka, north-western and western provinces in Zambia. Data analysis was performed by both descriptive and inferential statistics. Knowledge levels in malaria with regards to the mosquito being the vector and the capacity of malaria to kill were high in all the provinces and did not vary statistically. The two main sources of malaria information by weighted analysis were health facility and community health workers (CHWs). From the regression analysis, pain killer use was associated with high incomes, employment, secondary education, or higher, and the knowledge of fever as a sign for malaria. Additionally, the source of malaria information was related to education levels. There is a need to enhance information through available channels such as health facilities and $\mathrm{CHWs}$ and tailor them according to general education levels of a community.

Keywords: attitudes, community, knowledge, malaria, practices, Zambia

\begin{abstract}
Introduction
Malaria is a major cause of morbidity and mortality throughout Zambia. In 2007, four million suspected malaria cases and 6000 deaths ${ }^{1}$ were reported, while in 2010 the disease accounted for an annual reported incidence of 330 cases per $1000 .^{2}$ The disease transmission levels vary depending mainly on environmental factors, including disasters, ${ }^{3}$ which influence the availability of vectors. The three components in the malaria transmission triangle - the host, the parasite and the vector - all interact within the influence of environmental factors. The contribution of the host has a distinct role in the transmission process, based on its capacity to affect the reservoir base of parasites. ${ }^{4}$ Knowledge in malaria reinforces the capacity of the host to affect transmission intensity through informing attitudes and behaviour. ${ }^{5}$ Communities cooperating with health facilities and related structures such as the community health workers (CHWs) have recorded strides in malaria prevention and control ${ }^{5}$ have a unique role to play.
\end{abstract}

Zambia is considered among the leading nations in malaria control, ${ }^{1,6}$ and the efforts demonstrated attest to the fact. The fight against malaria in Zambia has been supported through global funding, and local state efforts with tremendous enabling factors in terms of good governance and political will. ${ }^{6}$ Knowledge studies have been conducted in Zambia from as far back as the late 1990s, ${ }^{7,8}$ and contribute to the understanding of community determinants of malaria; although, as in Swaziland, ${ }^{9}$ it is only recently that the importance of these studies has been recognised for use in control efforts in Zambia. ${ }^{10,11}$ The nation has also made strides in reaching the global World Health Organisation (WHO) targets in control, ${ }^{12}$ including long-lasting insecticide-treated net (ITN) distribution, high indoor residual spray (IRS) coverage and treatment.
There have been varying reports regarding the knowledge on malaria in different communities around the world, with some studies reporting improvements in the knowledge of the mosquito as the vector, although that knowledge did not translate to an improvement in intervention uptake. ${ }^{13,14}$ On the other hand, others have demonstrated the relationship between knowledge on malaria and the malaria prevention and control practices in communities. ${ }^{15}$

Studies involving community knowledge, attitudes and practices have shown that factors, ${ }^{16,17}$ including education levels in some, are related to behaviour in malaria control. ${ }^{16}$ It is clear that a change in behaviour is an important component in malaria prevention and control, but the basis of the behaviour elucidated by determining the levels of malaria knowledge and the attitude and practices of the community is even more crucial.

Our study sought to determine the level of malaria knowledge, attitude and practices (KAP) related to malaria with regards to its transmission and control in four malaria endemic provinces in Zambia.

\section{Methods}

\section{Study area}

Zambia is a landlocked country surrounded by eight neighbouring countries. ${ }^{18}$ The country is located in southern Africa between latitudes $-8^{\circ}$ and $-18^{\circ}$ South and longitudes $22^{\circ}$ and $34^{\circ}$ East. $^{18}$ The population in Zambia, according to the Census of 2010, is estimated at 13046508 people, $^{19}$ all of whom are at risk of malaria. ${ }^{20}$ The disease peaks during the rainy season and its burden is generally higher in rural compared to urban areas. ${ }^{21}$ As recommended by the WHO, cases of malaria are mainly detected when patients visit a healthcare facility for treatment, although surveillance detection also occurs. ${ }^{22}$ 


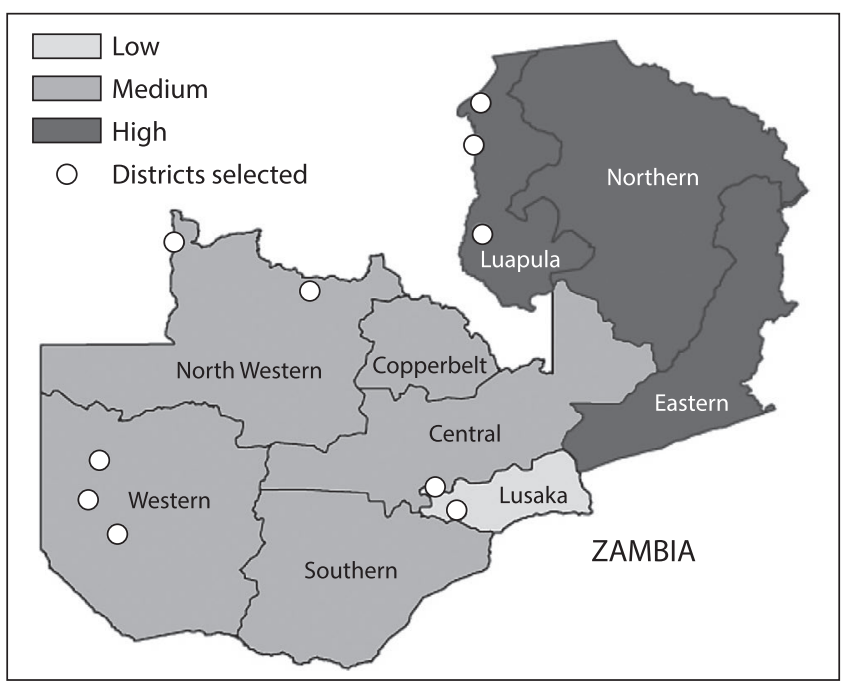

Figure 1: Map of the study sites in the three malaria transmission zones.

\section{Study frame}

We randomly selected 584 households as follows: Lusaka (LS) 311, North-western (NW) - 106, Western (W) - 105 and Luapula (LP) - 62 households, with the provinces representing the low (Zone I), low to moderate (Zone II) and moderate to high (Zone III) transmission zones, ${ }^{23}$ respectively. A sampling frame with implicit stratification was created for each of the four provinces and Standard Enumeration Areas (SEAs) selected (Figure 1) independently based on standard procedure. ${ }^{24}$

Each selected SEA on the frame had information on the province, district, constituency, ward, region, and Census Supervisory Area (CSA) where it is located. Systematic randomisation ${ }^{21}$ was conducted at the SEA level for the selection of households.

\section{Sample size}

This was calculated based on another study to determine the prevalence of uncomplicated malaria in the study population assuming that $6 \%$ of clinical malaria cases would result in uncomplicated malaria, ${ }^{25,26}$ and using a prevalence of $2.1 \%$ :

Sample size $(n)=Z^{2}[P(1-P)] / D^{2}$;

where $\mathrm{Z}=$ the critical value, $\mathrm{P}=$ the proportion of patients with uncomplicated malaria (2.1\%) and $D=$ the margin of error. ${ }^{27}$ Malaria Indicator Survey (MIS) malaria prevalence for each province $^{28}$ and the average number of persons per household ${ }^{21}$ were used to obtain the samples.

This study was conducted in one province of each of the three transmission zones. An extra province was selected in the low to moderate transmission zone by design in order to compensate for the greater number of provinces in the low to moderate zone. ${ }^{23}$

\section{Study design and data collection}

This study was a cross-sectional survey conducted from November 2013 to January 2014.

\section{Questionnaire administration}

The questionnaire was in English but was administered by two trained enumerators from the Zambian Central Statistical Office (CSO) at the various local offices in each province, facilitating accurate translation of the questionnaire in each community.
Translations were agreed upon for uniformity before the study in each of the provinces. This process was monitored by a study supervisor. Verbal consent to interview was obtained before a questionnaire was administered.

\section{Data analysis}

Weighted chi-square test and logistic regression in STATA 11 at $95 \%$ confidence level were used.

\section{Sample weights}

In order for the survey estimates to be representative of the population within each province, it was necessary to weigh the sample data. ${ }^{24}$

\section{Results}

\section{Study population}

Out of the 584 household heads interviewed from the four provinces, $76.3 \%$ were males and $23.7 \%$ were females, with a mean age of 41.9 years (range: $17-85$ years; standard deviation: 13.8). Table 1, using weighted chi-square values, shows the demographic characteristics of the study population including the level of education, occupation and income level.

\section{Knowledge and attitudes to malaria and source of information}

Out of the 584 household heads interviewed in all the four provinces, $97.4 \%$ had heard about malaria; the majority of them through the health facility $\left(\chi^{2}=14.5 ; p=0.002\right.$; Table 2; Figure 2$)$.

Table 3, by weighted analysis, shows that newspapers and television as sources of malaria information were significantly related to education, income and employment levels. Household heads that reported significantly higher use of television and newspaper as sources of malaria information had tertiary education ( $p=0.0005$ and $p<0.0001)$, incomes higher than ZMK 60000 per annum $(p=0.0001$ and $p<0.0001)$, and were employed $(p=0.04$ and $p<0.0001)$.

By further analysis, the contribution by healthcare facility as a source of information was statistically ranked as the highest (healthcare facility 59.9\%: 95\% Cl 50.3-69.5; CHW 16.6\%: 95\% Cl 9.3-23.9; radio 6.9\%: 95\% Cl 1.9-11.9; television 5.4\%: 95\% Cl 1.09.8; malaria group 3.9\%: 95\% Cl 0.1-7.7; church 2.7\%: 95\% Cl 0.55.9; community leadership 1.7\%: $95 \% \mathrm{Cl} 0.8-4.2$; family member 1.2\%: $95 \% \mathrm{Cl} 0.9-3.3$; friend 1.1\%: $95 \% \mathrm{Cl} 0.9-3.1$; school 0.5\%: $95 \% \mathrm{Cl} 0.9-1.9$; newspaper $0.1 \%$ : $95 \% \mathrm{Cl} 0.5-0.7)$. Figure 3 shows the signs and symptoms of malaria known.

\section{Attitudes and practices in malaria control and prevention}

Table 4 (by weighted analysis) shows attitudes and practices in malaria control and that $64.2 \%$ of the study population would attend formal health facilities and health posts within $24 \mathrm{~h}$ of noticing malaria signs ( $p=0.0007)$, although only $6.4 \%$ would use antimalarial drugs as an alternative to attending a health facility $(p<0.0001)$. Table 5 shows the relationship between ITN possession and education levels.

\section{Association of practices with knowledge and attitudes}

Table 6 relates practices with knowledge and attitudes as follows: attending formal health facilities and health posts early, and the use of pain killers as an alternative to attending formal health 
facilities and health posts. The latter was higher in household heads who had secondary education and higher $\left(62 \% ; \chi^{2}=14.1\right.$; $p=0.0002)$ and the employed than in the unemployed $(76.8 \%$; $\left.\chi^{2}=36 ; p<0.0001\right)$. The use of Coartem antimalarial medicine as an alternative to attending the formal health facilities and health posts was higher $\left(57.1 \% ; \chi^{2}=8.7 ; p=0.003\right)$ among the household heads who were unemployed. Seeking malaria treatment within $24 \mathrm{~h}$ of noticing malaria symptoms $\left(74.2 \% ; \chi^{2}=10.9 ; p=0.01\right)$ and antimalarial use as an alternative to attending formal health facilities $\left(52.4 \% ; \chi^{2}=41.8 ; p<0.0001\right)$ were significantly related to interaction with community social structures, such as community health workers.

There was a relationship between education levels and owning an ITN (56.5\%; $\left.\chi^{2}=4.6 ; p=0.03\right)$. IRS acceptance was higher among the unemployed $\left(26.1 \% ; \chi^{2}=5.9 ; p=0.02\right)$ and among those who knew the mosquito was a vector $\left(91.9 \% ; \chi^{2}=38.3\right.$; $p=0.008$ ).

\section{Discussion}

In this study, the age of the youngest household head observed in Lusaka and North-western provinces was 17 years; it is a rare occurrence to have young adults heading households, especially in urban Zambia. ${ }^{29}$

The population in Zambia is dominated by females $(51-53 \%),{ }^{21,28}$ yet household headship rests heavily on males $(74.9 \%),{ }^{28,30}$ as also demonstrated in our study, where $66-87 \%$ household heads were male.

Knowledge of the mosquito as a vector of malaria was quite high $(89.6 \%)$ in comparison with the $1 \%$ found in the Mporokoso and Choma districts in 2000. ${ }^{8}$ Our findings were comparable with $85 \%$ obtained in another study, ${ }^{16}$ and in other studies in which the knowledge levels varied $27-99 \% .{ }^{9-33}$ In our study, Lusaka and Luapula provinces recorded the lowest proportion; and, for Lusaka, this is explained to some extent by successful malaria control efforts. In spite of knowledge, correct behaviour in certain cases is hindered by a lack of or limited malaria experience, ${ }^{15,34}$ although it has further been suggested that malaria knowledge tends to reduce with the lowering of malaria levels. ${ }^{9}$ This further justifies the suggestion that improvement in knowledge, attitudes and practices related to malaria may be attained after considering its predictors at micro-level. ${ }^{35}$

Regardless of the low knowledge levels in the previous study in Zambia ${ }^{7}$ in comparison to our study, the finding that education is not related to malaria knowledge levels remains constant. This is also in agreement with one study ${ }^{16}$ but not another where only knowledge on preventive methods was inversely related to education levels $\mathrm{s}^{32}$ demonstrating no advantage of higher education levels in knowledge and practices in malaria control. The latter was implied in our study, as well as others, ${ }^{16,33}$ where most household heads who knew the capacity of malaria to kill were from rural areas where education levels are lower, and high knowledge was attributed to high endemicity of the disease. ${ }^{33}$ We agree with findings that formal education does not relate significantly with malaria risk. ${ }^{16,17}$ Furthermore, other studies recommended that improving the manner in which information reaches the communities with special attention to illiterate community members and tailor-made messages to encourage hanging up ITNs which would bridge owning and use were still necessary. ${ }^{17,36}$ Kaona and Tuba found that training motivators and vendors were contributing to compliance with standard therapeutic doses and correct identification of malaria. ${ }^{11}$ Another study showed that community health education can help improve health seeking behaviour. ${ }^{37}$

Additionally, other studies revealed that illiteracy with regards to health education ${ }^{31}$ is an important factor to guiding behaviour change messages, 32,33,38 and [Mwanje, personal communication, 2013] as well as taking socioeconomic and sociocultural aspects of particular communities into consideration in developing tailor-made interventions to avoid disrupting economic and cultural activities, and hence succeed with community commitment. ${ }^{13,14}$ Kaona et al. showed that age and literacy had no effect on people's health seeking behaviour, yet community health education was inevitable. ${ }^{7}$ As such, they recommended that motivators and vendors are trained accordingly.

Our study, in agreement with another, revealed that the main source of malaria information and known signs, i.e. fever, headache and body aches, were from health facilities, ${ }^{7}$ with fever being prominent in line with other studies. ${ }^{16,33,39,40}$ This shows Zambia's success in the "all households must know fever as a key predictor of malaria" policy ${ }^{30}$; although, it has been shown elsewhere that this predictor fails in children with diarrhoea. ${ }^{41}$ Headache and body aches were symptoms that were significantly related with higher education levels in our study. The source of this knowledge may need to be investigated, as well as the implication it may have on the attitudes and practices against the widely known symptom: fever.

Attitude, "a compound of affect, cognition and behaviour"42 is an important component in malaria control although it has not been adequately considered in the design of interventions such as health education promotion messages, hindering sustainable control. ${ }^{43}$ With regards to seeking treatment early and from health facilities, those with higher levels of education displayed an attitude of complacency, possibly owing to easy access to alternative treatment, a finding specifically true for Lusaka province. In agreement with another study, most participants with primary education and below attended healthcare facilities early, ${ }^{9}$ whereas another study showed only a few participants visited healthcare facilities early. ${ }^{14}$ Based on our regression analysis, and other findings, ${ }^{44}$, [Mwanje, personal communication, 2013] a correlation between increased knowledge and good treatmentseeking behaviour was demonstrated. However, the translation of knowledge to improved practice was inadequate. We demonstrated that interaction with community health workers was significantly related with seeking malaria treatment early, as well as using antimalarial drugs as an alternative to seeking healthcare from formal health facilities. Other studies have also demonstrated failure at translating knowledge into prevention practices, [Mwanje, personal communication, 2013] when preferring home treatment regardless of condition ${ }^{15}$; in insisting on chloroquine as an antimalarial therapy based on attitudes ${ }^{45}$; and, in understanding what aspects of malaria were important, such as differentiating mosquitoes as a nuisance as opposed to mosquitoes as a source of infection. ${ }^{44}$ Further, Zurovac and others found that although the use of chloroquine for uncomplicated malaria was successfully discontinued in Zambia, the change of policy to treatment with artemether did not translate to adequate point-of-care use of the drug, where both chloroquine and sulphadoxine pyrimethamine in conjunction with artemether lumefantrine were in use. ${ }^{46}$ These authors ${ }^{46}$ and others ${ }^{47}$ also found that patients were more ready to accept the new treatment than health workers. 
Table 1: Demographic characteristics of household heads selected in the study ${ }^{\text {a }}$

\begin{tabular}{|c|c|c|c|c|c|c|}
\hline & Luapula & Lusaka & N-western & Western & Total & $p$-value \\
\hline \multicolumn{7}{|l|}{ Characteristics } \\
\hline Mean age range in years & $22-78$ & $17-85$ & $19-85$ & $20-84$ & & \\
\hline \multicolumn{7}{|l|}{ Gender } \\
\hline Male & 66.2 & 79.3 & 87.4 & 64.8 & 76.3 & 0.002 \\
\hline Female & 33.8 & 20.7 & 12.6 & 35.2 & 23.7 & \\
\hline Total & 100 & 100 & 100 & 100 & 100 & \\
\hline $95 \% \mathrm{Cl}$ & $56.9-75.5$ & $71.4-87.2$ & $80.9-93.9$ & $55.4-74.2$ & & \\
\hline
\end{tabular}

Education

\begin{tabular}{|l|}
\hline Primary $\&<$ \\
\hline Secondary \\
\hline Tertiary \\
\hline Crafts \\
\hline Other \\
\hline Not known \\
\hline Total \\
\hline $95 \% \mathrm{Cl}$ \\
\hline
\end{tabular}

\begin{tabular}{|c|}
\hline 70.2 \\
\hline 28.8 \\
\hline 0 \\
\hline 0 \\
\hline 0 \\
\hline 0.9 \\
\hline 100 \\
\hline $61.2-79.2$ \\
\hline
\end{tabular}

\begin{tabular}{|c|c|}
\hline 28.8 & 64.1 \\
\hline 42.9 & 27.8 \\
\hline 13.5 & 3.4 \\
\hline 5.0 & 0 \\
\hline 0.7 & 0 \\
\hline 9.2 & 4.7 \\
\hline 100 & 100 \\
\hline $19.4-37.0$ & $54.7-73.5$ \\
\hline
\end{tabular}

\begin{tabular}{|c|}
\hline 59.7 \\
\hline 29.8 \\
\hline 8.6 \\
\hline 0 \\
\hline 0 \\
\hline 1.8 \\
\hline 100 \\
\hline $50.1-69.3$ \\
\hline
\end{tabular}

\begin{tabular}{|l|l|}
\hline 45.5 & $<0.0001$ \\
\hline 36.4 & \\
\hline 9.0 & \\
\hline 2.7 & \\
\hline 0.4 & \\
\hline 6.1 & \\
\hline 100 & \\
\hline
\end{tabular}

Occupation

\begin{tabular}{|c|c|c|c|c|c|c|}
\hline Unemployed* & 73.6 & 15.8 & 34.3 & 72.6 & 36.5 & $<0.0001$ \\
\hline Trained Employee & 3.8 & 23.8 & 2.0 & 4.6 & 14.4 & \\
\hline Small trader & 19.6 & 21.3 & 11.5 & 6.8 & 17.4 & \\
\hline Civil servant & 1.5 & 2.0 & 4.1 & 4.0 & 2.5 & \\
\hline Other** & 1.5 & 37.1 & 48.1 & 12.0 & 29.2 & \\
\hline Total & 100 & 100 & 100 & 100 & 100 & \\
\hline $95 \% \mathrm{Cl}$ & $65.0-82.2$ & $8.7-22.9$ & $25.0-43.6$ & $63.9-81.3$ & & \\
\hline \multicolumn{7}{|l|}{ Income $Z M W^{* * *}$} \\
\hline Above 12,000 & 0 & 1.0 & 0 & 0 & 0.5 & $<0.0001$ \\
\hline $60,000-119,999$ & 0 & 1.9 & 0 & 0 & 1.0 & \\
\hline $36,000-59,999$ & 1.5 & 4.7 & 4.1 & 0.8 & 3.5 & \\
\hline $12,000-35,999$ & 3.8 & 22.3 & 4.8 & 3.3 & 13.8 & \\
\hline $4,800-11,999$ \& below $* * * *$ & 94.7 & 70.1 & 91.1 & 95.9 & 81.2 & \\
\hline Total & 100 & 100 & 100 & 100 & 100 & \\
\hline $95 \% \mathrm{Cl}$ & $90.3-99.1$ & $61.1-79.1$ & $85.5-96.7$ & $92.0-99.8$ & & \\
\hline
\end{tabular}

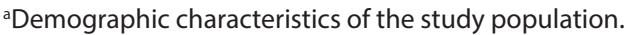

*Unemployed including subsistence farmers, overage and invalids.

**Other (occupation) including farm workers, military, retired and fishing.

***(1 USD $\approx 5$ ZMW in 2014).

****Minimum wage and below.

Further, our analysis showed that high income, employment and a higher level of education were positively related to use of pain killers, while unemployment was positively related to use of antimalarial medication, demonstrating that economically advantaged household heads took their elite status for granted by neglecting to practice good treatment seeking measures. Additionally, our study demonstrated that the unemployed who accessed antimalarial drugs did so through their interaction with community health workers who visited communities on a regular basis to provide information and proper treatment for malaria. We also demonstrated that sources of malaria information were related to education levels and, as such, policy makers may need to tailor information packages according to the general level of education in a particular area.
While accounting for cultural beliefs in the design of control measures and messages is critical, ${ }^{48}$ regional differences in terms of malaria transmission levels and region-specific cultural backgrounds must be considered. . $^{16,49}$ Other constraints to fully achieving the Ministry of Health $(\mathrm{MOH})$ goals are "presence of malaria in remote areas with limited access to health and education services, political instability", which also vary by region. ${ }^{16}$ Our study highlights such realities in Western and North-western provinces where access to healthcare and education is limited, and further recommends investigation into the basis of behavioural challenges revealed in low community uptake of appropriate control services in areas like Lusaka province, even when available. 
Table 2: Knowledge about malaria among household heads selected in the study

\begin{tabular}{|c|c|c|c|c|c|c|}
\hline & Luapula & Lusaka & $\mathrm{N}$-western & Western & Total & $p$-value \\
\hline \multicolumn{7}{|c|}{ Has respondent heard of malaria? } \\
\hline Yes & 100 & 98.4 & 90.6 & 100 & 97.4 & \\
\hline No & 0 & 1.6 & 9.4 & 0 & 2.6 & \\
\hline Total & 100 & 100 & 100 & 100 & 100 & \\
\hline \multicolumn{7}{|l|}{ Heard from? } \\
\hline Friend & 32.3 & 23.2 & 17.9 & 12.4 & 21.2 & 0.002 \\
\hline Family member & 4.8 & 15.4 & 1.9 & 12.4 & 11.3 & \\
\hline Pamphlet & 1.6 & 1.9 & 0.0 & 1.9 & 1.5 & \\
\hline Newspaper & 0.0 & 1.6 & 0.0 & 1.9 & 1.2 & \\
\hline Radio & 58.1 & 37.0 & 40.6 & 52.4 & 42.6 & \\
\hline Television & 0.0 & 27.3 & 0.9 & 5.7 & 15.8 & \\
\hline School & 1.6 & 5.5 & 2.8 & 3.8 & 4.3 & \\
\hline Church & 19.4 & 8.0 & 17.0 & 1.0 & 9.6 & \\
\hline Community & 21.0 & 16.1 & 20.8 & 18.1 & 17.8 & \\
\hline Health Facility & 91.9 & 69.1 & 76.4 & 47.6 & 69.0 & \\
\hline $\mathrm{CHW}$ & 33.9 & 4.5 & 10.4 & 48.6 & 16.6 & \\
\hline Malaria group & 25.8 & 2.6 & 0.9 & 1.0 & 4.5 & \\
\hline \multicolumn{7}{|c|}{ What transmits malaria? (weighted data) } \\
\hline Mosquito & 85.6 & 87.5 & 96.4 & 91.8 & 89.1 & 0.009 \\
\hline Untreated drinking water & 2.4 & 5.5 & 0 & 0.8 & 3.5 & \\
\hline Poor hygiene & 0 & 0.3 & 0 & 0 & 0.1 & \\
\hline Stagnant water & 0 & 2.5 & 0.7 & 2.9 & 1.9 & \\
\hline Dirty surroundings & 0 & 0.6 & 0 & 1.1 & 0.5 & \\
\hline It just comes & 0 & 0.4 & 0 & 0 & 0.2 & \\
\hline Rain & 3.5 & 0.5 & 0 & 0 & 0.8 & \\
\hline Not sure & 0 & 0.4 & 0 & 0 & 0.2 & \\
\hline Trees & 0 & 0.4 & 0 & 0 & 0.2 & \\
\hline Dirty food & 0 & 0.4 & 0 & 0 & 0.2 & \\
\hline Weather & 0.9 & 0.4 & 0 & 0 & 0.3 & \\
\hline Do not know & 7.7 & 1.1 & 2.9 & 3.4 & 2.8 & \\
\hline Total & 100 & 100 & 100 & 100 & 100 & \\
\hline $95 \% \mathrm{Cl}$ & $78.7-92.5$ & $81.0-94.0$ & $92.7-100.1$ & $86.4-97.2$ & & \\
\hline \multicolumn{7}{|c|}{ Can malaria kill? (weighted data) } \\
\hline Yes & 100 & 95.7 & 99.3 & 99.2 & 97.5 & 0.02 \\
\hline No & 0 & 2.8 & 0 & 0 & 1.5 & \\
\hline \multirow[t]{2}{*}{ Do not know } & 0 & 1.6 & 0.7 & 0.8 & 1.1 & \\
\hline & 100 & 100 & 100 & 100 & 100 & \\
\hline $95 \% \mathrm{Cl}$ & 100 & $91.7-99.7$ & $97.7-100.9$ & $97.5-100.9$ & & \\
\hline \multicolumn{7}{|l|}{ What are the signs of malaria } \\
\hline Fever & 100 & 89.4 & 89.6 & 77.1 & 88.4 & 0.01 \\
\hline Headache & 21.0 & 67.8 & 54.7 & 77.1 & 62.2 & \\
\hline Body ache & 22.6 & 54.7 & 51.9 & 61.0 & 51.9 & \\
\hline Chills & 0.0 & 19.0 & 5.7 & 26.7 & 15.9 & \\
\hline Vomiting & 59.7 & 34.1 & 40.6 & 28.6 & 37.0 & \\
\hline General malaise & 21.0 & 3.9 & 8.5 & 18.1 & 9.1 & \\
\hline Appetite loss & 35.5 & 11.6 & 16.0 & 23.8 & 17.1 & \\
\hline Dizzy & 14.5 & 5.8 & 7.5 & 17.1 & 9.1 & \\
\hline Other & 0.0 & 10.3 & 0.0 & 2.9 & 6.0 & \\
\hline
\end{tabular}


Table 2: (Continued)

\begin{tabular}{|c|c|c|c|c|c|c|}
\hline & Luapula & Lusaka & N-western & Western & Total & $p$-value \\
\hline \multicolumn{7}{|c|}{ Households have enough malaria info? (weighted data) } \\
\hline Yes & 79.3 & 90.5 & 85.4 & 35.5 & 79.6 & $<0.0001$ \\
\hline No & 20.7 & 8.9 & 13.5 & 62.7 & 19.7 & \\
\hline \multirow[t]{2}{*}{ Do not know } & 0 & 0.5 & 1.1 & 1.8 & 0.7 & \\
\hline & 100 & 100 & 100 & 100 & 100 & \\
\hline $95 \% \mathrm{Cl}$ & $71.4-87.2$ & $84.8-96.2$ & $78.5-92.3$ & $26.1-44.9$ & & \\
\hline
\end{tabular}

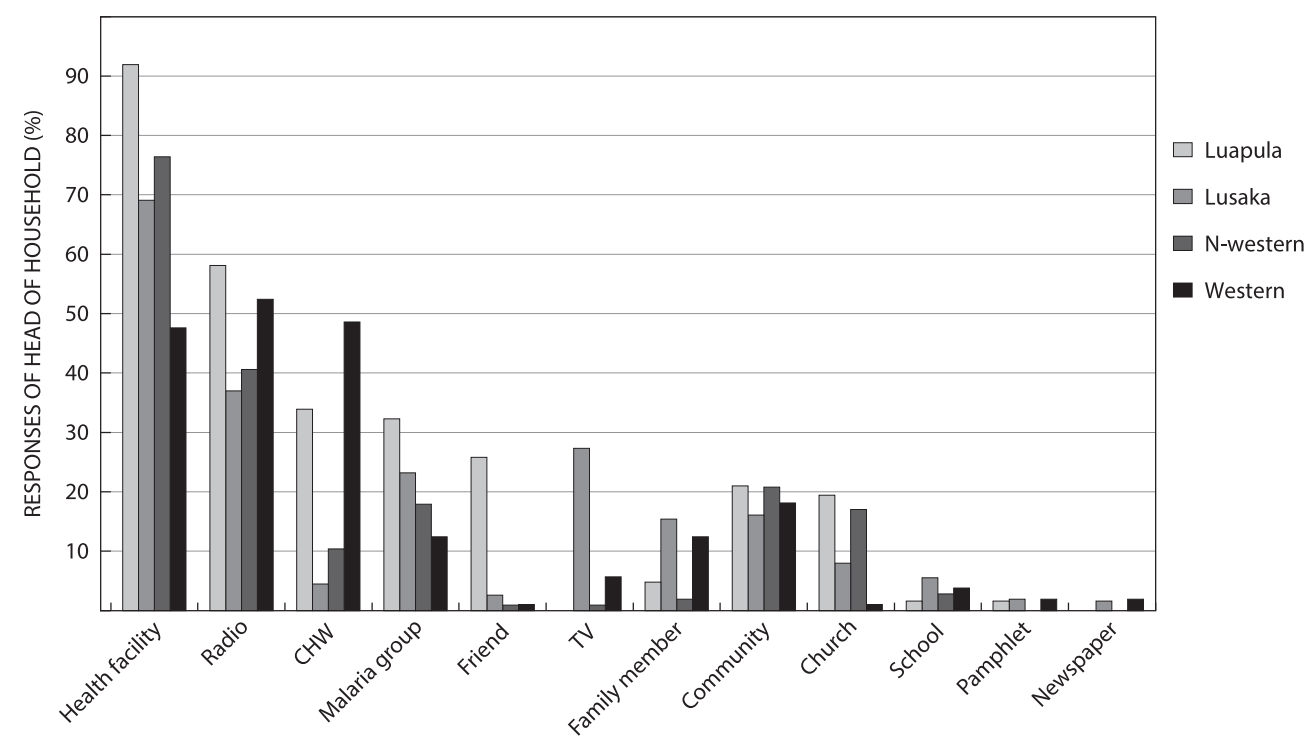

SOURCES OF MALARIA INFORMATION

Figure 2: Sources of malaria information among household heads.

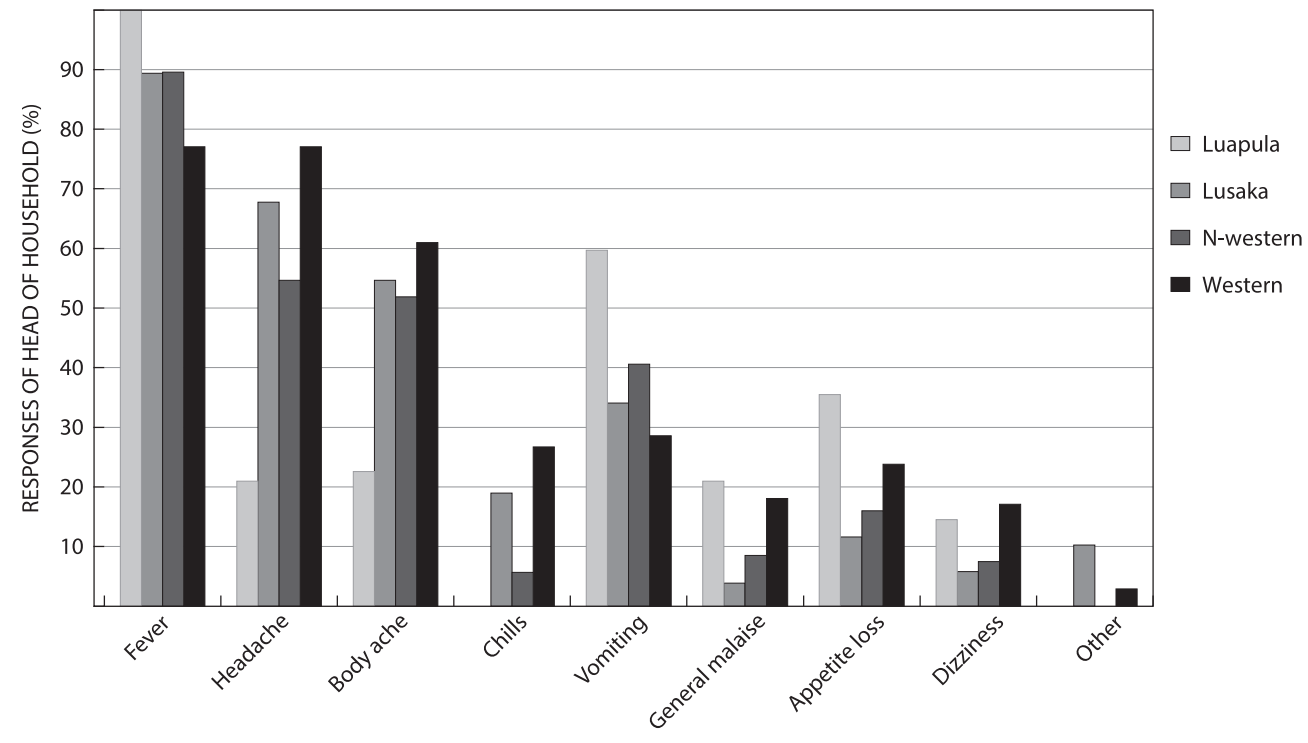

MALARIA SYMPTOMS KNOWN

Figure 3: Signs and symptoms of malaria among household heads. 
Table 3: Relationship between education level and information source (weighted data)

\begin{tabular}{|c|c|c|c|c|c|c|c|c|c|c|c|c|}
\hline & $\begin{array}{l}\text { Health } \\
\text { Facility }\end{array}$ & CHW & Radio & TV & $\begin{array}{c}\text { Malaria } \\
\text { group }\end{array}$ & Church & $\begin{array}{l}\text { Community } \\
\text { leadership }\end{array}$ & $\begin{array}{l}\text { Family } \\
\text { member }\end{array}$ & Friend & School & $\begin{array}{l}\text { News } \\
\text { paper }\end{array}$ & Total \\
\hline $\begin{array}{l}\text { Primary } \\
\text { educa- } \\
\text { tion and } \\
\text { below }\end{array}$ & 58.3 & 19.7 & 8.8 & 1.4 & 4.3 & 3.9 & 1.6 & 1.0 & 1.0 & 0 & 0 & 100 \\
\hline Secondary & 61.8 & 15.5 & 4.4 & 8.3 & 4.0 & 2.0 & 1.9 & 1.2 & 0.9 & 0 & 0 & 100 \\
\hline Tertiary & 63.2 & 10.4 & 2.6 & 11.5 & 2.6 & 0 & 1.5 & 1.5 & 0 & 5.1 & 1.5 & 100 \\
\hline Crafts & 49.3 & 0 & 23.3 & 11.8 & 0 & 0 & 0 & 3.9 & 11.6 & 0 & 0 & 100 \\
\hline Total & 59.9 & 16.6 & 6.9 & 5.4 & 3.9 & 2.7 & 1.7 & 1.2 & 1.1 & 0.5 & 0.1 & 100 \\
\hline
\end{tabular}

Furthermore, $85.8 \%$ household heads in our study believed malaria was preventable, $92.7 \%$ of which believed it was preventable by ITNs. Other studies ${ }^{9,31}$ also reported higher proportions ( $78 \%$ and $90.1 \%$, respectively) in that regard, although the proportion of those who believed it was preventable by ITN were low (15.6\%). ${ }^{9}$

With regards to owning and use of ITNs, the proportion of fathers owning ITNs was higher than all family members. Additionally, in provinces where proportions of mothers owning ITNs were higher than all categories, fathers were still next in line. The use of ITNs among the households that reported owning them was quite high (61.5\%). It has been recommended that efforts to educate communities, particularly women who are already convinced of their vulnerability, would yield more results in appropriate and vulnerable groups ${ }^{9}$ if made consistently over time. ${ }^{36}$ We concur with the recommendation that delivering educational information on malaria knowledge to women can help increase ITN ownership and use. ${ }^{15}$

Although a good number of ITNs were reported among the unemployed, our study further showed a significant relationship between having an ITN and attaining secondary education or higher. The high ITN proportions among the unemployed is attributed to the MOH ITN distribution campaigns in Zambia, which have made a significant contribution in equity in ITN ownership, increasing coverage from $38 \%$ in 2006 to $64 \%$ in $2010 .{ }^{10}$ We attribute our regression analysis findings of household heads with secondary and tertiary education levels more likely having ITNs compared to those with lower education to individual effort in acquiring current ITNs given the possibility of wear and tear of MOH ITNs distributed as early as 2005. ${ }^{50}$

A number of participants equated owning an ITN to receiving it as a donation, and never considered purchasing one as an option. This attitude was reflected in studies where individuals would not seek out testing or treatment even when services were subsidised mainly because the services were not absolutely free $^{51}$ and in which respondents reported that they could not afford to purchase an ITN. ${ }^{31}$ Free distribution of ITNs could be leading communities to develop a dependency on handouts, so a balance must be achieved because it is important to maintain the use of ITNs in endemic areas as a way of maintaining protection in case of disasters. Sustainability of the ITN effect has been demonstrated in some disaster areas in Zambia where malaria prevalence did not increase amidst disasters owing to use of ITN and other measures. ${ }^{3}$

Attitude to and acceptability of IRS in our study was determined based on the experience that community members had with the most recent spray, and also reasons advanced by household heads for their displeasure with the spray service. Our study is in agreement with another, ${ }^{14}$ which showed that the reasons given against IRS did not hinder acceptability as it was higher in areas of low development and education like the Luapula and Western provinces. However, sustainability is not guaranteed without behaviour assessment, interventions and change considering that houses in such areas are often re-plastered owing to low understanding of, and sometimes necessitated by, the short-term nature of muddy structures, ${ }^{31}$ thereby negating the IRS effect.

Factors that influence malaria control vary not only between but also within transmission zones, as was the case with differences in education levels, knowledge, attitudes and practices between Lusaka and North-western provinces versus Luapula and Western provinces, agreeing with one study that "there is no universal truth with regards to utilisation of healthcare" and that "every situation and every district has its own specific characteristics which make the outcome of decision-making process different every time..152 Our study revealed the unique factors that influence malaria transmission and control in various zones which must be addressed with tailor-made measures at the lowest level. This must be done while taking into account behaviour change, an underlying factor in all intervention efforts.

\section{Conclusion}

Our study is the first to study knowledge, attitudes and practices in malaria control simultaneously in various endemic provinces representing the formal stratification of malaria transmission zones in Zambia. We demonstrate that malaria knowledge, attitudes and practices with regards to transmission and control in the three transmission zones were similar in some respects, but varied in levels at province level. Community members demonstrated knowledge although disjointed with practices in access and use of protection or treatment. Therefore, information through available channels such as health facilities, radio and CHWs depending on local settings must be enhanced and the process must be based on area-specific tailor-made strategies given that malaria knowledge is low in low transmission zones. There is need to scale up IRS coverage as well as ITN use considering that, from our study, IRS coverage was quite low; and, although ITN coverage was higher, the ITNs could have been old and worn out: a factor compounded by apathy for personal procurement. We further recommend enhanced community-level efforts to assess needs and cover the different communities with befitting protection. Socio-cultural issues along with factors such as distance to health facilities and environmental issues which remain unique for the various zones must also be considered in malaria control. 
Table 4: Attitudes and practices in malaria control among household heads selected in the study

\begin{tabular}{|c|c|c|c|c|c|c|}
\hline & Luapula & Lusaka & $\mathrm{N}$-western & Western & Total & $p$-value \\
\hline \multicolumn{7}{|c|}{ How soon do household heads seek treatment } \\
\hline One day (within $24 \mathrm{~h}$ ) & 84.9 & 55.7 & 66.3 & 69.7 & 64.2 & 0.0007 \\
\hline $2-3$ days & 13.7 & 41.6 & 33.7 & 27.4 & 33.7 & \\
\hline $4-6$ days & 1.5 & 1.0 & 0 & 0 & 0.8 & \\
\hline \multirow[t]{2}{*}{7 days or more } & 0 & 1.7 & 0 & 2.2 & 1.2 & \\
\hline & 100 & 100 & 100 & 100 & 100 & \\
\hline $95 \% \mathrm{Cl}$ & $77.9-91.9$ & $46.0-65.4$ & $57.0-75.6$ & $60.7-78.7$ & & \\
\hline \multicolumn{7}{|c|}{ Alternative to seeking treatment } \\
\hline Nothing other than $\mathrm{HF}$ & 41.3 & 23.0 & 40.7 & 54.7 & 33.4 & $<0.0001$ \\
\hline Antimalarial & 5.0 & 3.9 & 0.7 & 22.5 & 6.4 & \\
\hline Pain killers & 45.2 & 61.9 & 45.3 & 4.3 & 48.0 & \\
\hline Traditional antimalarial & 8.6 & 6.7 & 13.3 & 18.5 & 9.7 & \\
\hline \multirow[t]{2}{*}{ Other } & 0 & 4.5 & 0 & 0 & 2.4 & \\
\hline & 100 & 100 & 100 & 100 & 100 & \\
\hline $95 \% \mathrm{Cl}$ & $0.7-9.3$ & $0.1-7.7$ & $-0.9-2.3$ & $14.3-30.7$ & & \\
\hline \multicolumn{7}{|l|}{ Malaria preventable } \\
\hline Yes & 86.1 & 82.6 & 88.8 & 94.2 & 85.8 & 0.12 \\
\hline No & 13.0 & 15.9 & 8.8 & 3.9 & 12.6 & \\
\hline \multirow[t]{2}{*}{ Do not know } & 0.9 & 1.5 & 2.5 & 1.9 & 1.6 & \\
\hline & 100 & 100 & 100 & 100 & 100 & \\
\hline $95 \% \mathrm{Cl}$ & $79.3-92.9$ & $75.2-90$ & $82.6-95$ & $89.6-98.8$ & & \\
\hline
\end{tabular}

Personal protection believed in for malaria prevention among heads who believed malaria was preventable

\begin{tabular}{|l|c|c|c|c|c|c|}
\hline Coil & 0 & 3.2 & 0 & 0 & 1.7 & $<0.0001$ \\
\hline Aerosol spray (Doom) & 0 & 5.3 & 0 & 0 & 2.8 \\
\hline Burning cow dung or other organic & 6.9 & 0.5 & 0 & 0 & 1.3 \\
\hline Closing windows & 3.2 & 0 & 7.4 & 0 & 1.5 & \\
\hline ITNs & 89.9 & 91.1 & 92.6 & 100 & 92.7 \\
\hline
\end{tabular}

Have bed nets?

\begin{tabular}{|c|c|c|c|c|c|c|}
\hline Yes & 63.7 & 65.3 & 51.9 & 98.5 & 68.0 & $<0.0001$ \\
\hline No & 36.3 & 34.7 & 48.1 & 1.6 & 32.0 \\
\hline & 100 & 100 & 100 & 100 & 100 \\
\hline $95 \% \mathrm{Cl}$ & $54.3-73.1$ & $56-74.6$ & $42.1-61.7$ & $96.1-100.9$ & \\
\hline
\end{tabular}

Who owns nets?

\begin{tabular}{|l|l|l|l|l|l|l|}
\hline Father & 33.9 & 51.1 & 43.4 & 61.9 & 49.8 \\
\hline Mother & 51.6 & 46.0 & 32.1 & 71.4 & 48.6 \\
\hline Children $>5$ yrs. & 22.6 & 28.9 & 18.9 & 41.0 & 28.6 \\
\hline Children $<5$ yrs. & 33.9 & 25.7 & 17.9 & 48.6 & 29.3 \\
\hline Other & 0.0 & 0.3 & 1.9 & 1.0 & 0.7 \\
\hline NA & 0.0 & 0.0 & 1.9 & 1.0 & 0.5 \\
\hline
\end{tabular}

\section{Bed nets all in use?}

\begin{tabular}{|c|c|c|c|c|c|c|}
\hline Yes & 63.6 & 58.0 & 42.5 & 89.4 & 61.5 & $<0.0001$ \\
\hline No & 0 & 4.9 & 11.9 & 9.0 & 5.7 & 32.8 \\
\hline NA & 36.4 & 37.1 & 45.6 & 1.6 & 100 \\
\hline & 100 & 100 & 100 & 100 & \\
\hline $95 \% \mathrm{Cl}$ & $54.2-73$ & $48.3-67.7$ & $32.8-52.2$ & $83.4-95.4$ & \\
\hline
\end{tabular}


Table 4: (Continued)

\begin{tabular}{|c|c|c|c|c|c|c|}
\hline & Luapula & Lusaka & N-western & Western & Total & $p$-value \\
\hline \multicolumn{7}{|c|}{ Happy with spray service } \\
\hline Yes & 37.4 & 18.9 & 17.6 & 24.8 & 22.8 & 0.003 \\
\hline No & 1.5 & 1.6 & 1.3 & 5.2 & 2.1 & \\
\hline \multirow[t]{2}{*}{ NA } & 61.2 & 79.5 & 81.2 & 69.9 & 75.1 & \\
\hline & 100 & 100 & 100 & 100 & 100 & \\
\hline $95 \% \mathrm{Cl}$ & $-0.9-3.9$ & $-0.9-4.1$ & $-0.9-3.5$ & $0.8-9.6$ & & \\
\hline
\end{tabular}

Table 5: Relationship between education level and ITN use (weighted data)

\begin{tabular}{|l|c|c|c|c|c|}
\hline All ITNs in use & Primary education and below & Secondary & Tertiary & Total \\
\hline Yes & 59.9 & 67.0 & 59.6 & 43.5 \\
\hline No & 3.5 & 5.4 & 22.8 & 3.9 \\
\hline NA & 36.6 & 27.6 & 17.6 & 5.1 \\
\hline Total & 100 & 100 & 100 & 100 \\
\hline $95 \% \mathrm{Cl}$ & $-0.1-7.1$ & $1-9.8$ & 100 \\
\hline
\end{tabular}

${ }^{*} p<0.0001$

Table 6: Relationship between knowledge and attitude with practices (odds ratios)

\begin{tabular}{|c|c|c|c|c|c|c|}
\hline & & Pain killers & Have ITN & Accept IRS & Use antimalarial med & Seek treatment in $24 \mathrm{~h}$ \\
\hline \multirow[t]{3}{*}{ High income } & OR & 1.6 & & & & \\
\hline & $P$ & 0.02 & & & & \\
\hline & $95 \% \mathrm{Cl}$ & $1.1-2.4$ & & & & \\
\hline \multirow[t]{3}{*}{ Employed } & OR & 2.8 & & & & \\
\hline & $P$ & $<0.0001$ & & & & \\
\hline & $95 \% \mathrm{Cl}$ & $1.9-3.9$ & & & & \\
\hline \multirow[t]{3}{*}{ Secondary \& above } & OR & 1.6 & 1.6 & & & \\
\hline & $P$ & 0.005 & 0.02 & & & \\
\hline & $95 \% \mathrm{Cl}$ & $1.2-2.2$ & $1.1-2.5$ & & & \\
\hline \multirow[t]{3}{*}{ Unemployed } & OR & & & 1.6 & 2.6 & \\
\hline & $P$ & & & 0.02 & 0.002 & \\
\hline & $95 \% \mathrm{Cl}$ & & & $1.1-2.5$ & $1.4-4.9$ & \\
\hline \multirow[t]{3}{*}{ Malaria can kill } & OR & & & & & 3.2 \\
\hline & $P$ & & & & & 0.009 \\
\hline & $95 \% \mathrm{Cl}$ & & & & & $1.3-7.8$ \\
\hline \multirow[t]{3}{*}{ Mosquito as vector } & OR & & & 1.9 & & \\
\hline & $\mathrm{P}$ & & & 0.01 & & \\
\hline & $95 \% \mathrm{Cl}$ & & & $1.1-3.2$ & & \\
\hline \multirow[t]{3}{*}{ Knowing fever } & OR & 2.2 & & & & \\
\hline & $P$ & 0.005 & & & & \\
\hline & $95 \% \mathrm{Cl}$ & $1.3-3.8$ & & & & \\
\hline
\end{tabular}

Competing interests - The authors declare that they have no competing interests in the manuscript.

Funding - This work is partly funded by University of KwaZuluNatal

Ethical Approval - The study protocol was approved by University of Zambia (UNZA) Biomedical Research Ethics Committee (IRB00001131 of IORG0000774).
Acknowledgements - This work is partly funded by University of KwaZulu-Natal being part of the requirements for fulfilment of a $\mathrm{PhD}$ degree in Parasitology at the same institution.

We acknowledge populations in the four provinces of Zambia who participated in the study and National Malaria Control Centre, Tropical Diseases Research Centre, University of Zambia, Ministry of Health including Provincial Health Offices and Central Statistical office including Provincial CSO Offices in Zambia, for 
administrative and other support. We further acknowledge Mr. Litia Simbangala and Mr. Godwin Sichone for statistical design and analysis support.

\section{Supplementary information}

The questionnaire can be found in the supplementary information available at: http://dx.doi.org/10.1080/23120053.20 16.1205330 .

\section{References}

1. World Health Organisation. Roll back malaria. Progress and impact country reports: Focus on Zambia. Geneva: World Health Organisation; 2011.

2. Government of the Republic of Zambia. MDG Zambia profile. Lusaka: United National Development Programme; 2013.

3. Zambia Vulnerability Assessment Committee. In-depth vulnerability and needs assessment report on the impact of floods and/or prolonged dry spells. Lusaka: Zambia Vulnerability Assessment Committee; 2007. Available from: http://m.wfp.org/content/zambiadepth-vulnerability-and-needs-assessment-report-august-2007.

4. WHO. Fact sheet. 2014 [cited 2015 Mar 5]. Available from: www.who. int/mediacentre/factsheets/fs094/en/.

5. Ludwick T, Brenner JL, Kyomuhangi T, et al. Poor retention does not have to be the rule: retention of volunteer community health workers in Uganda. Health Policy Plan. 2014;29(3):388-95.

6. Ashraf N, Fink G, Weil DN. Evaluating the effects of large scale health interventions in developing countries: the Zambia malaria initiative. NBER Working Paper 16069. JEL No. I18; 2010.

7. Kaona FAD, Siziya $S$, Mushanga $M$. The problems of a social survey in epidemiology: An experience from a Zambian rural community. Afr J Med Med Sci. 1990;19(3):219-24.

8. Kaona F, Siajunza MT, Manyando $C$, et al. Utilisation of malarial drugs at a household level: results from a KAP study inChoma, southern province and Mporokoso, northern province of Zambia. Cent Afr J Med. 2000;46(10):268-70.

9. Hlongwana KW, Mabaso MLH, Kunene $\mathrm{S}$, et al. Community knowledge, attitudes and practices (KAP) on malaria in Swaziland: A country earmarked for malaria elimination. Malar J. 2009;8:29. http://dx.doi.org/10.1186/1475-2875-8-29

10. Chanda E, Kamuliwo M, Steketee RW, et al. An overview of the malaria control programme in Zambia. ISRN Preventive Medicine. 2013; Article ID 495037.

11. Kaona FAD, Tuba M. Improving ability to identify malaria and correctly use chloroquine in children at household level in Nakonde District, Northern Province of Zambia. Malar J. 2003;2(1):43. doi: 10.1186/1475-2875-2-43.

12. Pylypchuk Y, Norton SW. Preventing malaria among children in Zambia: the role of mother's knowledge. Health Econ. 2015;1389-402. http://dx.doi.org/10.1002/hec.3093

13. Laar AS, Laar AK, Dalinjong PA. Community perception of malaria and its influence on health-seeking behaviour in rural Ghana: a descriptive study. Malaria World Journal 2013;4:1.

14. Aderaw Z, Gedefaw M. Knowledge, attitude and practice of the community towards malaria prevention and control options in antimalaria association intervention zones of amahara national regional state, Ethiopia. J Trop Dis. 2013;1:118.

15. Hwang J, Graves PM, Jima D, et al. Knowledge of malaria and its association with malaria-related behaviours-results from the malaria indicator survey, Ethiopia. Public Library Of Science ONE 2010;5(7):e11692.

16. Forero DA, Chaparro PE, Vallejo AF, et al. Knowledge, attitudes and practices of malaria in Colombia. Malar J. 2014;13:165. http://dx.doi.org/10.1186/1475-2875-13-165

17. Mazigo HD, Obasy E, Mauka W, et al. Knowledge, attitudes, and practices about malaria and its control in rural Northwest Tanzania. Malar Res Treat. 2010; Article ID 794261.

18. Africa-EU Energy Partnership. Power Sector Market Brief: Zambia. Eschborn, 2013 [cited 2015 Mar 20] 11:03. Available from: http:// www.euei-pdf.org/sites/default/files/files/field_pblctn_file/AEEP_ Zambia_Power\%20Sector\%20Market\%20Brief_Dec2013_EN.pdf.
19. Government of Zambia, Central Statistical Office. 2010 census of population and housing. Lusaka: Central Statistical Office; 2012.

20. Zambia Malaria Operational Plan. President's malaria initiative. PMI initiatives in Zambia. Fighting malaria and saving lives. Zambia profile. Washington, DC: U.S. Agency for International Development; 2014 [cited 2015 Mar 20]. Available from: http://www.pmi.gov/docs/ default-source/default-document-library/malaria-operational-plans/ fy14/zambia_mop_fy14.pdf?sfvrsn=8.

21. Chimumbwa JM. The epidemiology of malaria in Zambia. PhD Thesis. University of KwaZulu-Natal; 2003 [cited 2015 Mar 26]. Available from: http://researchspace.ukzn.ac.za/xmlui/handle/10413/4150.

22. World Health Organisation. Disease surveillance for malaria elimination. An operational manual. Geneva: World Health Organisation; 2012.

23. Masaninga F, Chanda E, Chanda-Kapata P, et al. Review of the malaria epidemiology and trends in Zambia. Asian Pacific Journal of Tropical Biomedicine 2013;3(2):89-94.

24. United Nations. Household sample surveys in developing and transition countries. Studies in methods. Series F No. 96. ST/ESA/ STAT/SER F/96. New York (NY): Department of Economic and Social Affairs Statistics Division; 2005.

25. Zambia Ministry of Health (M.O.H.). Malaria prevalence rates in Lusaka 2006/2007 season. Lusaka: Ministry of Health; 2007.

26. World Health Organisation. Roll Back Malaria. Progress and Impact Series. Country Reports Number 2 - Focus on Zambia. Geneva: World Health Organisation; 2011.

27. Dell RB, Holleran S, Ramakrishnan R. Sample size determination. Inst of Lab Anim Resours J. 2002;43(4):207-13.

28. Government of Zambia, Ministry of Health. Malaria indicator survey. Lusaka: Ministry of Health; 2010.

29. United Nations World Food Programme. Annual report. Rome: UNWFP; 2006.

30. Government of Zambia, Central Statistical Office, et al. Zambia demographic and health survey. Lusaka: Central Statistical Office; 2009.

31. Joshi AB, Banjara MR. Malaria related knowledge, practices and behaviour of people in Nepal. J Vector Borne Dis. 2008 Mar;45:44-50.

32. Shey DN, Njunda AL, Kamga HLF, et al. Knowledge and practices relating to malaria in Ndu community of Cameroon: signs and symptoms, causes and prevention. J Public Health and Epidemiol. 2011;3(6):294-300.

33. Rakhshani F, Ansari Moghadam AR, Alemi R, et al. Knowledge, perceptions and prevention of malaria among women in Sistan va Baluchestan, Islamic Republic of Iran. East Mediterr Health J. 2003;9(3):248-56.

34. Enato EFO, Okhamafe AO, Okpere EE. A survey of knowledge, attitude and practice of malaria management among pregnant women from two health care facilities in Nigeria. Acta Obstetricia et Gynecologica. 2007;86:33-6.

35. Sharma AK, Bhasin S, Chaturvedi S. Predictors of knowledge about malaria in India. J Vector Borne Dis. 2007;44:189-97.

36. Macintyre K, Littrell M, Keating J, et al. Determinants of hanging and use of ITNs context of near universal coverage in Zambia. Health Policy Plann. 2012;27:316-25.

37. Silweya D, Baboo KS. Barriers to prompt malaria treatment among under five children in Mpika district. Med J Zambia 2013;40:40-4. No 4.121-1250047-651X0047-651X.

38. Kimbi HK, Nkesa SB, Ndamukong-Nyanga JL, et al. Knowledge and perceptions towards malaria prevention among vulnerable groups in the Buea Health District, Cameroon. BMC Public Health 2014;14:883. http://dx.doi.org/10.1186/1471-2458-14-883

39. Bouyou-Akotet MK, Offouga CL, Mawili-Mboumba DP, et al. Falciparum malaria as an emerging cause of fever in adults living in Gabon, Central Africa. Biomed Res Int. 2014; Article ID 351281.

40. Iroezindu MO, Agaba El, Okeke EN, et al. Relationship Between Fever and Malaria Parasitaemia in Adults: Does HIV infection Make any Difference? J Med Trop. 2012;14(2):103-8.

41. Gbadegesin RA, Adeyemo SO, Ademowo OG. Body temperature is a poor predictor of malaria parasitaemia in children with acute diarrhoea. Ann Trop Paediatr. 1997;10:89-94.

42. Pickens J. Attitudes and perceptions. In: Borkowski N, editor. Organizational behavior in health care. Sudbury, MA: Jones and Bartlett Publishers; 2005 [cited 2015 Oct 21], Chapter 3 pp. 43-76. Available from: http://healthadmin.jbpub.com/Borkowski/chapter3.pdf. 
43. Habtai H, Ghebremeskel T, Mihreteab S, et al. Knowledge, attitudes and practices (KAP) about malaria among people visiting referral hospitals of Eritrea in 2008. J Eritrean Med Assoc. 2009;14(1):42-6.

44. Aikins MK, Pickering H, Greenwood BM. Attitudes to malaria, traditional practices and bed nets (mosquito nets) as vector control measures: a comparative study in five West African countries. J Trop Med Hyg. 1994;97(2):81-6.

45. Singh Sanjay, Ebere UkatuVictoria, Singh Rupashree, et al. Knowledge, attitude and practices on malaria among the rural communities in Aliero, Northern Nigeria. J Family Med Primary Care 2014;3(1):39-44. http://dx.doi.org/10.4103/2249-4863.130271

46. Zurovac D, Ndhlovu M, Rowe AK, et al. Treatment of paediatric malaria during a period of drug transition to artemether-lumefantrine in Zambia: cross sectional study. BMJ 2005;331(7519):734.

47. Sipilanyambe N, Chanda P, Wamulume P. Compliance to Coartem ${ }^{\circledast}$ for the treatment of uncomplicated Plasmodium falciparum malaria in Zambia [MIM-PW-302880] 096. Abstracts / Acta Tropica 95S 2005 [cited 2015 Apr 13];S1-S506. Available from: http:// www.mimalaria.org/eng/docs/pdfs/publications/Abstracts_MIM_ Yaounde_2005.pdf
48. Maslove DM, Mnyusiwalla A, Mills EJ, et al. Barriers to effective treatment and prevention of malaria in Africa; A systematic review of qualitative studies. BioMed Central International. Health and Hum rights 2009;9:26. doi: 10.1186/1472-698X-9-26.

49. Government of the Republic of Zambia. MDG Luapula Profile. UNDP; 2013

50. Chanda E, Coleman M, Kleinschmidt I, et al. Impact assessment of malaria vector control using routine surveillance data in Zambia: implications for monitoring and evaluation. Malar J. 2012;11:437. http://dx.doi.org/10.1186/1475-2875-11-437

51. Infanta Malaria Prevention Foundation. 2010 [cited 2015 Apr 13]. Available from http://infantamalaria.org/im_what_we_do.html.

52. Stekelenberg J. Health care seeking behaviour and utilisation of health services in Kalabo District, Zambia. Regenboog, Groningen: Stichting DrukkerijC; 2004.

Received: 20-12-2015 Accepted: 21-06-2016 